\title{
COVID-19 in adults: test menu for hospital blood science laboratories
}

\section{Paula M. O'Shea ${ }^{1}$ (D) - Graham Robert Lee ${ }^{2} \cdot$ Tomás P. Griffin $^{3} \cdot$ Vincent Tormey $^{4} \cdot$ Amjad Hayat $^{5} \cdot$ Seán J. Costelloe ${ }^{6}$. Damian Gerard Griffin ${ }^{1}$. Saradha Srinivasan ${ }^{7}$. Maurice O'Kane $^{8}$. Conor M. Burke ${ }^{9}$. John Faul ${ }^{9}$ • Christopher J. Thompson ${ }^{10} \cdot$ Gerard Curley $^{11} \cdot$ William P. Tormey ${ }^{7}$}

Received: 14 April 2020 / Accepted: 4 May 2020 / Published online: 18 May 2020

(C) Royal Academy of Medicine in Ireland 2020

\begin{abstract}
Introduction Coronavirus disease 2019 (COVID-19), is a respiratory illness caused by the novel severe acute respiratory syndrome coronavirus 2 (SARS-CoV-2). The Clinical Blood Sciences Laboratory (CBSL) plays a key role in supporting the monitoring and management of patients with COVID-19 disease.

Objective To provide a comprehensive CBSL testing protocol to support the medical management of SARS-CoV-2 infection. Methods Description of the biochemical, haematological and immunological tests that have a role in the assessment and monitoring of patients with COVID-19 infection.

Results We provide a test menu for clinical laboratories to ensure the effective monitoring, management and prognostication of COVID-19 patients in hospital.

Conclusion Given the rapidity with which patients with COVID-19 disease can deteriorate, we recommend regular testing with vigilance paid to the rate and trajectory of change in each of these parameters.
\end{abstract}

Keywords Blood science testing $\cdot$ COVID-19 $\cdot$ Hospital laboratories $\cdot$ Monitoring and management

\section{Background}

Coronavirus disease 2019 (COVID-19) is a respiratory illness caused by the novel severe acute respiratory syndrome coronavirus 2 (SARS-CoV-2). COVID-19 disease was first described in Wuhan, China in December 2019 and is now a global pandemic. As of the 12th of

Paula M. O'Shea

PaulaM.OShea@hse.ie

1 Department of Clinical Biochemistry, Saolta University Health Care Group (SUHCG), Galway University Hospitals, Newcastle Road, Galway, Ireland

2 Department of Clinical Biochemistry and Diagnostic Endocrinology, Mater Misericordiae University Hospital, Dublin, Ireland

3 Centre for Diabetes and Metabolism, SUHCG, Galway University Hospitals, Galway, Ireland

4 Department of Immunology, SUHCG, Galway University Hospitals, Galway, Ireland

5 Department of Haematology, University Hospital Galway, Galway, Ireland
April 2020, there were 1,696,588 confirmed COVID-19 cases worldwide, $10-15 \%$ of which have severe disease and over 105,952 deaths reported [1]. Most of those affected have milder illness $(80 \%), 15 \%$ are severely ill (require oxygen) and 5\% will require admission to the intensive care unit (ICU). The Clinical Blood Sciences Laboratory (CBSL) plays a key role in

6 Department of Clinical Biochemistry, Cork University Hospital, Cork, Ireland

7 Department of Chemical Pathology, Beaumont Hospital, Dublin 9, Ireland

8 Department of Clinical Chemistry, Altnagelvin Hospital, Derry, Northern Ireland

9 Department of Respiratory Medicine, Connolly Hospital Blanchardstown, Dublin 15, Ireland

10 Department of Endocrinology, Beaumont Hospital, Dublin 9, Ireland

11 Department of Anaesthesia and Critical Care, Royal College of Surgeons, Dublin, Ireland 
Table 1 Clinical blood science testing for COVID-19 patients in hospital

\begin{tabular}{|c|c|c|}
\hline Parameter & Abnormality & Utility for prognostication \\
\hline \multicolumn{3}{|l|}{ Biochemistry } \\
\hline \multicolumn{3}{|l|}{ Inflammatory biomarkers } \\
\hline Interleukin 6 & $\uparrow+$ Velocity & Hyperinflammatory syndrome \\
\hline Procalcitonin & $\uparrow+$ Velocity & Bacterial (Super) infection \\
\hline \multicolumn{3}{|l|}{ Acute phase proteins } \\
\hline C-reactive protein & $\uparrow$ & Inflammation/sepsis \\
\hline Albumin & $\downarrow$ & Response to severe inflammation \\
\hline Ferritin & $\uparrow$ & \\
\hline \multicolumn{3}{|l|}{ Lung } \\
\hline $\mathrm{pH}$ & $\uparrow$ & Assessment of pulmonary function \\
\hline Partial pressure of oxygen $\left(\mathrm{pO}_{2}\right)$ & $\downarrow$ & Check blood gases regularly (every 30 minutes if patient \\
\hline $\begin{array}{l}\text { Partial pressure of carbon dioxide } \\
\left(\mathrm{pCO}_{2}\right)\end{array}$ & $\downarrow$ & deteriorating) \\
\hline Bicarbonate $\left(\mathrm{HCO}_{3}\right)$ & $N / \uparrow$ & \\
\hline Fraction of inspired oxygen $\left(\mathrm{FIO}_{2}\right)$ & $\downarrow$ & \\
\hline Lactate & $\uparrow$ & \\
\hline \multicolumn{3}{|l|}{ Renal } \\
\hline \multirow[t]{2}{*}{ Electrolytes $\left(\mathrm{Na}^{+} / \mathrm{K}^{+} / \mathrm{CL}^{-}\right)$} & $\uparrow \mathrm{Na}^{+}$ & Insensible losses and diuretic therapy \\
\hline & & May portend acute kidney injury \\
\hline Urea & $\uparrow$ & Acute kidney injury (AKI) \\
\hline Creatinine (Cr) & $\uparrow$ & $\mathrm{Cr}$ increase $26 \mu \mathrm{mol} / \mathrm{L} / 48 \mathrm{~h}$; or $1.5 \times$ baseline $/ 7$ days \\
\hline \multicolumn{3}{|r|}{ 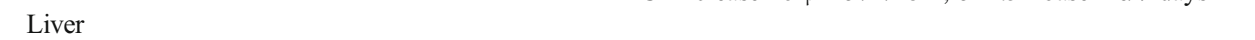 } \\
\hline Total bilirubin & $\uparrow$ & Liver injury \\
\hline Alanine transaminase (ALT) & $\uparrow$ & \\
\hline Aspartate aminotransferase (AST) & $\uparrow$ & \\
\hline Lactate dehydrogenase (LDH) & $\uparrow$ & Tissue damage/multiple organ failure \\
\hline \multicolumn{3}{|l|}{ Heart } \\
\hline High-sensitivity cardiac troponin & $\uparrow$ & Cardiac myositis/increased oxygen demand/inflammation \\
\hline B-type natriuretic peptide & $\uparrow$ & Severity of inflammation/ventricular dysfunction \\
\hline \multicolumn{3}{|l|}{ Other } \\
\hline Creatine phosphokinase (CPK) & $\uparrow$ & Muscle injury \\
\hline Triglycerides & $\uparrow$ & Increased lipolysis \\
\hline Glucose & $\mathrm{N} / \uparrow$ & Increased stress response \\
\hline Ionized calcium & $\downarrow$ & RI/impaired PTH action/chelation precipitation \\
\hline Phosphate & $\downarrow$ & Required for multiple enzyme function \\
\hline Magnesium & $\downarrow$ & \\
\hline Vitamin D (25(OH)D) & $\downarrow$ & Inflammatory response/decreased synthesis \\
\hline \multicolumn{3}{|l|}{ Haematology } \\
\hline \multicolumn{3}{|l|}{ Full blood count } \\
\hline White cell count (WCC) & $\uparrow$ & Response to bacterial infection \\
\hline Neutrophils & $\uparrow$ & \\
\hline Leucocytes & $\uparrow$ & \\
\hline Lymphocytes & $\downarrow$ & Immunological response to COVID-19 \\
\hline Platelets & $\mathrm{N} / \downarrow$ & Counts fall consequent to consumption/DIC \\
\hline \multicolumn{3}{|l|}{ Coagulation profile } \\
\hline D-dimers & $\uparrow$ & Activation of blood coagulation \\
\hline Fibrinogen & $\uparrow$ & Fibrinogen concentration falls in DIC or consumptive \\
\hline Prothrombin time $(\mathrm{PT})$ & $\uparrow$ & coagulopathy \\
\hline \multicolumn{3}{|l|}{ Immunology } \\
\hline \multicolumn{3}{|l|}{ Cytokine panel } \\
\hline IL-1 $\beta$, IL6, IL8, TNF- $\alpha$ & $\uparrow$ & Disease severity/cytokine storm syndrome \\
\hline
\end{tabular}

DIC disseminated intravascular coagulopathy, $N$ normal, $R I$ renal impairment, $P T H$ parathyroid hormone supporting the monitoring and management of COVID19 disease. Routine CBSL tests recommended to support medical decision-making and prognostication based on the current literature are detailed in Table 1 [2]. Recent evidence suggests that patients with severe
COVID-19 are at risk for cytokine storm syndrome [3] and that where possible, Interleukin 6 (IL-6) should be used to assess these patients for suspected hyperinflammation [3, 4]. Furthermore, elevated concentrations of procalcitonin (a peptide precursor of the 
hormone calcitonin) in the circulation is associated with $\sim 5$-fold higher risk of developing the severe form of the disease [5].

\section{Septic shock}

Septic shock in adults is recognised when infection is suspected or confirmed, lactate is $\geq 2 \mathrm{mmol} / \mathrm{L}$ and vasopressors are needed to maintain a mean arterial pressure (MAP) of $60-65 \mathrm{mmHg}$ in the absence of hypovolemia [6].

\section{Cytokine storm syndrome}

Inflammation is the body's first line of defence against infection, responding to challenges by activating innate and adaptive immune responses. Ironically, hyperinduction of proinflammatory cytokine production (cytokine storm syndrome) can put a patient at risk for complications associated with COVID-19. Early recognition of this possibility is required to inform management and treatment decisions. This is important as potential treatments with existing approved therapies with proven safety profiles such as tocilizumab (an IL-6 receptor blocker) and Janus kinase (JAK) inhibitors have been mooted to address the rising mortality in patients with COVID-19 pneumonia and elevated IL-6 [3]. Identifying patients to direct these specific treatments is aided by measuring C-reactive protein (CRP), interleukin 6 (IL-6), ferritin and procalcitonin. IL- 6 drives CRP and is an earlier marker of the status of a patients' inflammatory status. Elevated IL-6 concentrations together with the velocity of an increasing result portend an impending deterioration in clinical status.

Procalcitonin (PCT) is released into the circulation during bacterial infections and sustained by interleukins IL1- $\beta$, IL-6 and tumour necrosis factor alpha (TNF- $\alpha$ ). PCT is inhibited by interferon gamma (IFN- $\gamma$ ), the primary activator of macrophages and stimulator of natural killer cells and neutrophils. Hence, PCT levels should remain within the reference interval in uncomplicated COVID-19 disease. Markedly abnormal PCT results on the other hand are consistent with bacterial coinfection in those developing severe forms of the disease $[5,7-10]$.

\section{Lung}

Angiotensin-converting enzyme 2 (ACE2) is the functional receptor for SARS-CoV-2. Human tissue studies have determined that ACE2 is expressed in some 15 organs, including the heart, kidneys and lung [11]. ACE2 is a key counterregulatory enzyme of the renin-angiotensinaldosterone system (RAAS) that degrades angiotensin II to angiotensin-(1-7) reducing its effects on vasoconstriction, sodium retention and blood pressure. SARS-CoV-2 has a predilection for type II epithelial cells of the alveoli, with the lower airways being the dominant site of injury in COVID-19 [12]. The spectrum of COVID-19 lung illness spans asymptomatic infection and mild upper respiratory tract illness to severe viral pneumonia with respiratory failure and even death [13]. Arterial/venous blood gas parameters $\left(\mathrm{pH}, \mathrm{pO}_{2}, \mathrm{pCO}_{2}\right.$, $\mathrm{HCO}_{3}, \mathrm{FIO}_{2}$ and lactate) are used to monitor the patients' respiratory function and inform clinical decision-making. Criteria used to evaluate the severity of COVID-19 disease are detailed in Table 2 .

\section{Kidney: acute kidney injury}

Acute kidney injury (AKI) requiring dialysis is reported in a subset of patients admitted to ICU. The exact mechanism is unclear at this point, but AKI is present in $\sim 7 \%$ of patients with pathology demonstrating acute tubular necrosis. AKI correlates with an overall poor prognosis and seems to be the strongest predictor of mortality [14].

Many factors can affect the metabolism of creatinine from creatine in muscles and the rate of secretion of creatinine in the renal tubules, influencing both creatinine measurements and estimates of glomerular filtration rate (eGFR), the best overall index of kidney function. The National Kidney Foundation recommends using the Chronic Kidney DiseaseEpidemiology Collaboration (CKD-EPI) formula for eGFR [15]. However, the population used to derive this formula contained a limited number of elderly people and racial and ethnic minorities with measured GFR. Moreover, renal function in these patients is not in a steady state. Routine urine tests recommended to support medical decision-making are detailed in Table 3.

\section{Liver: hepatocyte injury and disseminated intravascular coagulopathy}

Elevated liver chemistries (alanine transaminase (ALT) aspartate aminotransferase (AST)) in COVID-19 disease are indicative of hepatocyte injury. While increased concentrations of bilirubin, prothrombin (a vitamin K-dependent coagulation factor) and fibrinogen (a 340-kDa glycoprotein) synthesised in the liver are indicative of liver dysfunction. Prothrombin is proteolytically cleaved to form thrombin which converts fibrinogen to fibrin and then to a fibrin-based blood clot to occlude blood vessels and arrest bleeding. A D-dimer is a fibrin degradation product present in the blood after a blood clot is degraded by fibrinolysis. In acute sepsis, the coagulation system becomes diffusely activated with consumption of multiple clotting factors resulting in disseminated intravascular coagulopathy (DIC) [16]. Pathogenesis is driven by an upregulation of procoagulant mechanisms and simultaneous downregulation of natural anticoagulants. The prevention of DIC in COVID-19 patients is critical to prevent multiorgan failure and efforts should centre on stratifying patients at high 
Table 2 Criteria used to evaluate the severity of COVID-19 patients in hospital

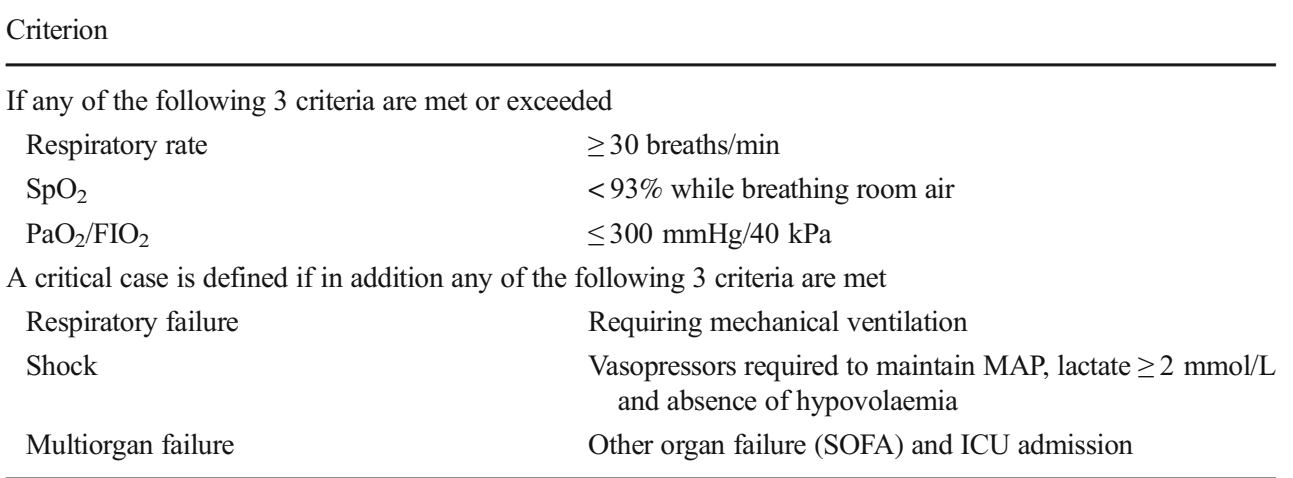

$\mathrm{SpO}_{2}$ peripheral capillary oxygen saturation (estimate of the amount of oxygen in blood), $\mathrm{PaO}_{2}$ partial pressure of oxygen in arterial blood, $\mathrm{FIO}_{2}$ : fraction of inspired oxygen, $M A P$ mean arterial pressure $(60-65 \mathrm{mmHg}), \mathrm{SOFA}$ sequential organ failure assessment risk for DIC. The prothrombin test (PT) (which measures the time it takes blood to clot (Normally: 11-12.5 s)), fibrinogen, D-dimers and the platelet count are significant predictors of disease severity as test abnormalities herald the onset of DIC. Klok et al. report a $31 \%$ incidence of thrombotic complications in ICU patients with COVID-19 and reinforce the recommendation for strict adherence to thrombosis prophylaxis [17].

\section{Heart: myocardial injury, high-sensitivity cardiac tro- ponin and B-type natriuretic peptide}

Clinical studies have demonstrated that patients with longterm coronary artery disease and those with risk factors for atherosclerotic cardiovascular disease (CVD) are at increased risk of developing an acute coronary syndrome during influenza [18, 19] and acute inflammatory infections [20]. The speculated mechanism is that severe systemic inflammation leads to atherosclerotic plaque instability and rupture. Elevated high-sensitivity cardiac troponin concentrations are indicative of myocardial injury. Shi et al. reported that greater proportions of COVID-19 patients with cardiac injury required non-invasive mechanical ventilation (38 of 82 [46.3\%] vs 13 of 334 [3.9\%]; $P<0.001)$ or invasive mechanical ventilation (18 of 82 [22.0\%] vs 14 of 334 [4.2\%]; $P<0.001)$ when compared to those without cardiac injury [21]. Further, that in this cohort, higher concentrations of high-sensitivity cardiac troponin were associated with higher
Table 3 Clinical laboratory urine testing of COVID-19 patients in hospital

\begin{tabular}{|c|c|c|}
\hline Urine parameter & Criterion value & Utility for prognostication \\
\hline Urine output & $\begin{array}{l}\text { Volume }<0.5 \mathrm{~mL} / \mathrm{kg} / \mathrm{h} \text { for } \\
\quad 6 \mathrm{~h}\end{array}$ & AKI \\
\hline \multicolumn{3}{|l|}{ Osmolality } \\
\hline \multirow[t]{2}{*}{$\begin{array}{l}\text { True hyponatraemia: } \\
\text { Serum } \mathrm{Na}^{+}:<133 \mathrm{mmol} / \mathrm{L}\end{array}$} & $>100 \mathrm{mOsm} / \mathrm{kg}$ & $\begin{array}{l}\text { Evidence of AVP action, from SIAD } \\
\text { or baroregulated AVP release } \\
\text { (hypotension/hypovolaemia) }\end{array}$ \\
\hline & $<100 \mathrm{mOsm} / \mathrm{kg}$ & Normal water excretion \\
\hline Spot urine $\mathrm{Na}^{+}$ & $<30 \mathrm{mmol} / \mathrm{L}$ & $>30 \mathrm{mmol} / \mathrm{L}$ \\
\hline Hypovolaemic & $\begin{array}{l}\text { Depletion: } \\
\text { GI/skin/mucosa/diuretics }\end{array}$ & $\begin{array}{l}\text { Addison's disease } \\
\text { CSWS/SWN/diuretics }\end{array}$ \\
\hline Euvolaemic & Hypothyroidism & SIADH \\
\hline & SIADH with fluid restriction & Hypopituitarism \\
\hline Hypervolaemic & Cirrhosis CCF & $\begin{array}{l}\text { Renal impairment CCF } \\
\text { Diuretics }\end{array}$ \\
\hline \multicolumn{3}{|l|}{ Proteinuria } \\
\hline $\begin{array}{l}\text { Albumin: creatinine ratio } \\
\text { (ACR) }\end{array}$ & $>30 \mathrm{mg} / \mathrm{mmol}$ & $\begin{array}{l}\text { Classification: degree of renal } \\
\text { impairment/target organ damage }\end{array}$ \\
\hline $\begin{array}{l}\text { Protein: creatinine ratio } \\
\text { (PCR) }\end{array}$ & $>15 \mathrm{mg} / \mathrm{mmol}$ & \\
\hline
\end{tabular}

$A K I$ acute kidney injury, SIAD syndrome of inappropriate antidiuresis, GI gastrointestinal, AVP arginine vasopressin, $C S W S$ cerebral salt wasting syndrome, $S W N$ salt wasting nephropathy, $C C F$ congestive cardiac failure 
mortality [21]. Ruan et al. also reported that patients with CVD infected with SARS-CoV-2 had a significantly increased risk of death [4]. These authors determined that some of their patients with SARS-CoV-2 died of fulminant myocarditis. Direct viral infection of the vascular epithelium and myocardium has been promulgated based on the unique affinity of SARS-CoV-2 for the host ACE2 receptor [22]. Hence, raising the possibility of myocarditis occurring in some COVID-19 patients irrespective of existing or pre-existing CVD [20, 21, 23].

Patients with heart failure are prone to haemodynamic decompensation and an unfavourable course when infected with SARS-CoV-2 [24]. Recent insights have been provided by Guo et al. demonstrating that cardiac troponin levels are significantly associated with C-reactive protein (CRP) and Btype natriuretic peptide, linking myocardial injury to severity of inflammation during hospitalisation in patients who follow a deteriorating clinical course toward death [25]. Patients with myocardial injury also have evidence of elevated leukocyte counts, CRP, procalcitonin (PCT) and creatinine phosphokinase (CPK).

\section{Muscle}

Muscle breakdown as evidenced by raised levels of creatine phosphokinase (CPK) and myoglobin has been reported to occur in patients with COVID-19 disease $[4,9,13]$.

\section{Vitamin D: 25(OH)D}

Vitamin D insufficiency/deficiency is a global health pandemic, more common in patients in nursing homes and inpatients than patients in the community or outpatients [26]. The older person is most vulnerable to COVID-19 and death $[9,13]$. Human dipeptidyl peptidase-4 receptor (DPP-4/CD26) binding has recently been shown to interact with the $\mathrm{S} 1$ domain of the COVID-19 spike glycoprotein, suggesting that it may be an important virulence factor in SARS-CoV-2 infection [27]. Of note, DPP-4/CD26 receptor expression has been shown to be significantly reduced in vivo on correction of vitamin $\mathrm{D}$ deficiency [28]. Vitamin D has also been shown to reduce IL6 production in monocytes [29]. This evidence provides a rationale for supplementing COVID-19-positive patients with vitamin D [30].

To conclude, this test menu covers the requirements to manage and assist prognostication of COVID-19 patients in hospital. Given the rapidity with which these patients can deteriorate, we recommend regular testing with vigilance paid to the rate and trajectory of change in each of these parameters.

Author contribution PMOS researched the literature and wrote the first draft of the manuscript. GL, VT, AH, SC, DG,SS, MOK, CB, JF, CT, GC
\& WPT critically revised and approved the final version the manuscript. Guarantor: PMOS.

\section{Compliance with ethical standards}

Competing interests The author(s) declares no potential conflict of interest.

Ethical approval Not applicable.

\section{References}

1. World Health Organization. Coronavirus disease 2019 (COVID19) Situation Report - 83. Available at: https://www.who.int/docs/ default-source/coronaviruse/situation-reports/20200412-sitrep-83covid-19.pdf?sfvrsn=697ce98d_4. Accesed: April 12, 2020

2. Lippi G, Plebani M (2020) The critical role of laboratory medicine during coronavirus disease 2019 (COVID-19) and other viral outbreaks. Clin Chem Lab Med. https://doi.org/10.1515/cclm-20200240

3. Mehta P, McAuley DF, Brown M et al (2020) COVID-19: consider cytokine storm syndromes and immunosuppression. Lancet 395 : 1033-1034

4. Ruan Q, Yang K, Wang W et al (2020) Clinical predictors of mortality due to COVID-19 based on an analysis of data of 150 patients from Wuhan, China. Intensive Care Med. https://doi.org/10.1007/ s00134-020-05991-x

5. Lippi G, Plebani M (2020) Procalcitonin in patients with severe coronavirus disease 2019 (COVID-19): a meta-analysis. Clin Chim Acta 505:190-191

6. Alhazzani W, Moller MH, Arabi YM et al (2020) Surviving Sepsis Campaign: Guidelines on the Management of Critically Ill Adults with Coronavirus Disease 2019 (COVID-19). Crit Care Med. https://doi.org/10.1097/CCM.0000000000004363

7. Lippi G, Plebani M (2020) Laboratory abnormalities in patients with COVID-2019 infection. Clin Chem Lab Med. https://doi.org/ 10.1515/cclm-2020-0198

8. Guan WJ, Ni ZY, Hu Y, China Medical Treatment Expert Group for Covid-19 et al (2020) Clinical characteristics of coronavirus disease 2019 in China. N Engl J Med 382:1708-1720

9. Huang C, Wang Y, Li X et al (2020) Clinical features of patients infected with 2019 novel coronavirus in Wuhan, China. Lancet 395: 497-506

10. Wang D, Hu B, Hu C et al (2020) Clinical Characteristics of 138 Hospitalized Patients With 2019 Novel Coronavirus-Infected Pneumonia in Wuhan, China. JAMA. https://doi.org/10.1001/ jama.2020.1585

11. Hamming I, Timens W, Bulthuis ML et al (2004) Tissue distribution of ACE2 protein, the functional receptor for SARS coronavirus. A first step in understanding SARS pathogenesis. J Pathol 203:631637

12. Vaduganathan M, Vardeny O, Michel T et al (2020) Reninangiotensin-aldosterone system inhibitors in patients with Covid19. N Engl J Med 382:1653-1659

13. Zhou F, Yu T, Du R et al (2020) Clinical course and risk factors for mortality of adult inpatients with COVID-19 in Wuhan, China: a retrospective cohort study. Lancet 395:1054-1062

14. Cheng Y, Luo R, Wang K et al (2020) Kidney disease is associated with in-hospital death of patients with COVID-19. Kidney Int 97: 829-838

15. Levey AS, Stevens LA, Schmid CH et al (2009) A new equation to estimate glomerular filtration rate. Ann Intern Med 150:604-612 
16. Simmons J, Pittet JF (2015) The coagulopathy of acute sepsis. Curr Opin Anaesthesiol 28:227-236

17. Klok FA, Kruip MJHA, van der Meer NJM et al (2020) Incidence of thrombotic complications in critically ill ICU patients with COVID-19. Thrombosis Research. https://doi.org/10.1016/j. thromres.2020.04.013

18. Kwong JC, Schwartz KL, Campitelli MA et al (2018) Acute myocardial infarction after laboratory-confirmed influenza infection. $\mathrm{N}$ Engl J Med 378:345-353

19. Nguyen JL, Yang W, Ito K et al (2016) Seasonal influenza infections and cardiovascular disease mortality. JAMA Cardiol 1:274281

20. Smeeth L, Thomas SL, Hall AJ et al (2004) Risk of myocardial infarction and stroke after acute infection or vaccination. N Engl J Med 351:2611-2618

21. Shi S, Qin M, Shen B et al (2020) Association of Cardiac Injury With Mortality in Hospitalized Patients With COVID-19 in Wuhan, China. JAMA Cardiol. https://doi.org/10.1001/jamacardio.2020. 0950

22. Gheblawi M, Wang K, Viveiros A et al (2020) Angiotensin Converting Enzyme 2: SARS-CoV-2 Receptor and Regulator of the Renin-Angiotensin System. Circ Res. https://doi.org/10.1161/ CIRCRESAHA.120.317015

23. Inciardi RM, Lupi L, Zaccone G et al (2020) Cardiac Involvement in a Patient With Coronavirus Disease 2019 (COVID-19). JAMA Cardiol. https://doi.org/10.1001/jamacardio.2020.1096

24. Bonow RO, Fonarow GC, O'Gara PT et al (2020) Association of Coronavirus Disease 2019 (COVID-19) With Myocardial Injury and Mortality. JAMA Cardiol. https://doi.org/10.1001/jamacardio. 2020.1105

25. Guo T, Fan Y, Chen M et al (2020) Cardiovascular Implications of Fatal Outcomes of Patients With Coronavirus Disease 2019 (COVID-19). JAMA Cardiol. https://doi.org/10.1001/jamacardio. 2020.1017

26. Griffin TP, Wall D, Blake L et al (2020) Vitamin D status of adults in the community, in outpatient clinics, in hospital and in nursing homes in the West of Ireland. J Gerontol A Biol Sci Med Sci. https://doi.org/10.1093/gerona/glaa010

27. Vankadari N, Wilce JA (2020) Emerging WuHan (COVID-19) coronavirus: glycan shield and structure prediction of spike glycoprotein and its interaction with human CD26. Emerg Microbes Infect 9: 601-604

28. Komolmit P, Charoensuk K, Thanapirom K et al (2017) Correction of vitamin D deficiency facilitated suppression of IP-10 and DPP IV levels in patients with chronic hepatitis C: a randomised doubleblinded, placebo-control trial. PLoS One 12:e0174608

29. Sadeghi K, Wessner B, Laggner U et al (2006) Vitamin D3 downregulates monocyte TLR expression and triggers hyporesponsiveness to pathogen-associated molecular patterns. Eur J Immunol 36: 361-370

30. McCartney DM, Byrne DG (2020) Optimisation of vitamin D status for enhanced immuno-protection against Covid-19. Ir Med J 113:58

Publisher's note Springer Nature remains neutral with regard to jurisdictional claims in published maps and institutional affiliations. 